\title{
As Contribuições da Psicologia Cognitiva e a Atuação do Psicólogo no Contexto Escolar
}

\author{
Mônica F. B. Correia \\ Universidade Federal da Paraíba \\ Anna Paula Brito Lima \\ Universidade Federal Rural de Pernambuco \\ Claudia Roberta de Araújo \\ Universidade Federal Rural de Pernambuco
}

\begin{abstract}
Resumo
Este artigo propõe uma discussão acerca do papel do psicólogo no contexto escolar, a partir da análise das principais teorias que hoje permeiam o debate em educação. Os psicólogos escolares têm, ao longo do seu tempo de inserção nesse contexto, centrado suas preocupações principalmente nas dificuldades de aprendizagem dos alunos, numa atuação individualizada e setorizada. Contudo, este papel necessita ser redimensionado, uma vez que aquele deveria ter formação teórica que instrumentalizasse a sua participação ativa nas discussões acerca do processo ensino-aprendizagem, atuando na "situação didática" — com alunos, com professores; enfim, com toda a comunidade escolar, dentro de um tempo historicamente determinado.

Palavras-chave: Atuação do psicólogo; contexto escolar; teorias psicogenéticas.
\end{abstract}

Cognitive Psychology Contributions and the Psychologist's Role in the School Context

\begin{abstract}
This article proposes a discussion concerning the psychologist's role and function in the school context, from the standpoint of the analysis of the main theories that today permeate the debate in education. The school psychologists have, along their time of insertion in that context, worried themselves with difficulties of student learning, in an individualized, sectorized performance. However, this role needs to be redimensioned, once the psychologist should have a theoretical formation that would instrumentalize the active participation in the discussions concerning the teaching-learning process, acting in the "didactic situation" - with the students, with the teachers, finally with the whole school community, inside of a historically determined time.

Keywords: Psychologist's role; school context; psychogenetic theories.
\end{abstract}

Este artigo tem por objetivo, analisar uma proposta de atuação para o psicólogo escolar, bem como as principais teorias que permeiam os discursos relacionados à Educação, principalmente porque esta discussão - sobre as contribuições da Psicologia Cognitiva - tem se mostrado alheia ao cotidiano deste profissional. Procuramos, dentro das limitações de um artigo, despertar os leitores para a problemática da atuação e para a necessidade de aproximarmos, nesta atuação, as tão relevantes contribuições da Psicologia do cenário escolar. Para tanto, o texto foi organizado em quatro partes. A primeira traz uma proposta de atuação para o psicólogo no contexto escolar, na qual percebemos a necessidade do conhecimento daquelas contribuições da Psicologia Cognitiva. Nas segunda e terceira seções, destacamos alguns conceitos deste conhecimento, aqueles que

\footnotetext{
${ }^{1}$ Endereço para correspondência: Av. Abdias Gomes de Almeida, 997, Tambauzinho, 58042-100, João Pessoa, Pb. Fone: (83) 2438622, Fax (83) 2167064.E-mail: moncorreia@uol.com.br
}

consideramos essenciais, e suas implicações no contexto escolar. Por fim, fazemos considerações relevantes a todos os tópicos discutidos nas seções anteriores.

\section{A Atuação do Psicólogo no Contexto Escolar}

$\mathrm{Na}$ compilação de estudos sobre as relações entre cultura e cognição e sobre a prática dos psicólogos do Brasil no cenário escolar, observa-se um descompasso. As idéias que ampliaram nossos conhecimentos a respeito da cognição humana não são compartilhadas em um dos contextos mais férteis para sua discussão - a escola - e cujo objetivo, supostamente, seria a promoção de desenvolvimento e aprendizagem. As investigações e atuações junto à Educação confirmam o desconhecimento e até a deturpação de idéias centrais sobre a construção do conhecimento, especialmente entre os psicólogos inseridos neste contexto, profissionais que deveriam atuar como mediadores entre tais conhecimentos e a Educação.

Correia (1997; Correia, Oliveira \& Andrade, 1998) verificou, por exemplo, que as escolas, tanto particulares 
quanto públicas, investem em capacitações de professores, mas os psicólogos só são apontados timidamente como responsáveis por estas. Em contrapartida, são citados, com considerável ênfase, quando os entrevistados são colocados numa situação de encaminhar o aluno para um profissional fora da escola. Neste sentido, parece que o psicólogo escolar está tornando-se invisível na escola, tanto para atuar com problemas emocionais, de acordo com uma antiga visão, como - continua esquecido para atuar com a construção do conhecimento ou processos cognitivos.

A Psicologia Escolar ainda se caracteriza, predominantemente, por uma atuação centrada basicamente naquele aluno apontado como "problemático", ou seja, aquele que "não pára quieto", que "não aprende", que é "agressivo" e que atrapalha a transmissão do conteúdo ou o cumprimento do programa na sala de aula. E na história da sua inserção no contexto escolar, discutida por Correia e Campos (2000) e resumida aqui, encontramos várias posturas, como o modelo médico de atuação, o modelo do engenheiro humano, ou seja, modificador de comportamentos, até aqueles, como diz Patto (1984), em níveis mais sofisticados, que fazem terapia na escola ou lidam com outros personagens além do aluno.

Moreira (1994) traz uma questão interessante referente à relação do fracasso escolar com a atuação do psicólogo: “... como explicá-lo sem ferir os meandros da estrutura escolar? É este o pedido endereçado à Psicologia” (p.6). A qual, infelizmente, tem procurado atender a este pedido, focalizando no indivíduo todas as "culpas" de seu fracasso e do caótico sistema escolar. Assim, a freqüência dos psicólogos escolares no cenário educacional é bastante diversificada, fundamentada por teorias que indicam que devemos desde aplicar testes até trabalhar especificamente com professores, embora a ênfase geralmente esteja no indivíduo. Entretanto, o que se verifica é uma atuação alheia a toda uma conjuntura, na forma de um trabalho eminentemente clínico nas escolas. Em outras palavras, a figura de marketing ou decorativa tem sido a posição cumprida por muitos dos psicólogos nas escolas, uma vez que geralmente não sabem qual a sua função nesta instituição (Correia \& Campos, 2000). Há vários fatores (história, pluralidade teórica, formação, legislação) que contribuem para uma atuação insatisfatória, em conseqüência dos quais ainda podemos caracterizar a Psicologia Escolar pelas controvérsias, pouca objetividade, indefinição e insegurança com relação à atuação: o quê produzir neste cenário?

Muitos autores compartilham da idéia de que o principal objetivo do psicólogo escolar deveria ser aumentar a qualidade e eficiência do processo ensino- aprendizagem. Mas, geralmente, não há consenso ou clareza quando a questão é "como" intervir neste processo. A literatura cita inúmeras funções que o psicólogo poderia assumir na instituição escolar e ao mesmo tempo reivindica um único caminho. No entanto, não podem existir delimitações, uma vez que deveria ser essencialmente contextualizada, ou seja, partir das necessidades e prioridades emergentes em cada escola. Esta característica impede que tenhamos algo como uma lista de procedimentos padrões para a atuação do psicólogo escolar. Ele deverá primeiramente questionar quais são os setores que estão requerendo intervenções e quais destas são as prioritárias, sempre tendo em vista a eficiência do processo ensino-aprendizagem.

Correia e Campos (2000) propõem, então, uma atuação mais objetiva e completa, representada por um esquema sobre o que, efetivamente, o psicólogo poderia fazer na instituição escolar. Tal esquema resume as principais diretrizes para esta atuação (Figura 1).

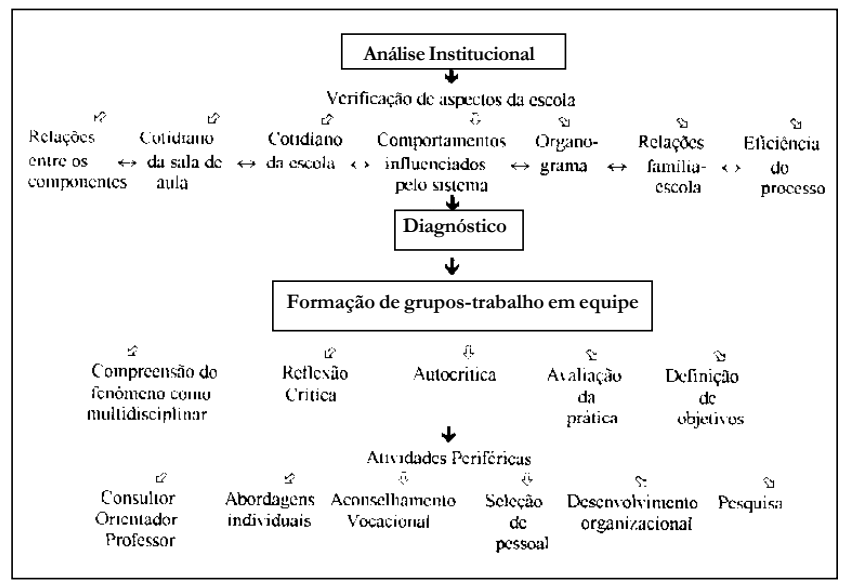

Figuia 1. Esquemà-síntese da atuação do psicólogo escolar (adaptado de Correia \& Campos, 2000)

Ao ingressar em uma escola, o psicólogo deverá iniciar a sua atuação pela "análise da instituição". Essa análise envolverá todos os setores e indivíduos que compõem a escola, bem como as suas inter-relações, e tem por objetivo observar as relações, levantar evidências sobre qual a referência teórica que fundamenta a postura e a ação dos professores e dos seus dirigentes, a coerência entre o discurso e a prática dos seus componentes; o que por sua vez também reflete o nível de conhecimento. Em suma, o psicólogo estará preocupado em "verificar os aspectos da escola", independentemente das queixas iniciais que geralmente tendem a focalizar os problemas no aluno.

Concluída aquela fase, haverá elementos que correlacionados irão auxiliar na análise sobre a "eficiência e qualidade do processo educacional" desenvolvido. A 
partir daí, começará a sugerir mudanças avaliadas como necessárias. Para tanto, o psicólogo apresentará uma outra característica fundamental da sua atuação: o "trabalho em equipe". Posteriormente aparecem as atividades denominadas "periféricas", que partem ou derivam das estruturais, com características e cuidados específicos (consultor, orientador, professor, atendimento individualizado ao aluno - abordado à luz da escola como um todo - aconselhamento vocacional, seleção de pessoal e desenvolvimento organizacional). Por último, é citada a atividade de pesquisa na escola, embora ela esteja relacionada a todos os aspectos levantados anteriormente, essencialmente àqueles que se denominam estruturais, uma vez que envolvem coleta e análise de dados.

Assim são enfatizados três pontos como sendo os mais relevantes para a prática do psicólogo no contexto educacional: 1) iniciar a ação pela análise da instituição, visto que cada escola é específica e apresentará prioridades também específicas; 2) não esquecer que o processo ensino-aprendizagem é dinâmico, em constante transformação; logo, não dispõe de procedimentos rígidos; 3) ter sempre em mente que o processo educacional apresenta-se como multidimensional, requisitando trabalho "em equipe".

As análises realizadas em escolas públicas ou particulares, baseadas nesta estrutura, (Correia, Lima \& Campos, 1999) geralmente têm apontado como prioritária a necessidade de fundamentação teórica entre os profissionais da Educação. O psicólogo escolar tem aparecido como necessário, principalmente, para mediar conhecimentos, aproximando daquele cenário as contribuições da Psicologia. Mas, em boa parte dos casos, os que estão na escola não têm se mostrado bons parceiros para esta mediação, sequer reconhecem tal necessidade.

Há um dado, comum às situações de transição, encontrado no cenário escolar: "ouve-se o galo cantar, mas não se sabe onde”. Em outras palavras, há uma necessidade de o psicólogo se inserir na escola como um personagem que retorna e instiga o retorno às contribuições da Psicologia, pois naquele cenário as idéias estão soltas, desarticuladas e precisam ser retomadas desde as considerações mais primárias ou elementares. Porque sem estas, todas as outras se tornam inócuas, gera-se um círculo de atividades no qual nenhuma mudança pode ser efetiva. Uma forma de iniciar, por exemplo, é pela reflexão das origens e influências (das correntes filosóficas empirista, inatista e interacionista) das abordagens do processo, uma vez que concebem a construção ou aquisição do conhecimento pelo homem de maneiras distintas e até contraditórias e, portanto, delegam papéis diferentes, em cada uma, a professores e a alunos.

Psicologia: Reflexão e Crítica, 2001, 14(3), pp. 553-561
Como a fundamentação teórica ou o conhecimento das contribuições da Psicologia Cognitiva tem sido um dos "vácuos" mais encontrados no contexto escolar, e caracteriza-se como um dos pilares desta proposta de atuação, decidimos abordar pontos importantes, portanto idéias férteis que precisam ser aprofundadas, discutidas sistematicamente e relacionadas ao cotidiano escolar. Estas idéias servem como ponto de partida e, ao mesmo tempo, denunciam o quão distante se está destas contribuições. Sem poderem servir, como sabemos, quais manuais de primeiros socorros, com imediata utilização ou aplicação.

Atualmente, nossas mais fortes contribuições originamse das teorias de Piaget e de Vygotsky. Tais estudiosos têm-se revelado pilares da nossa compreensão sobre "como o ser humano aprende" e fundamentam grande parte dos projetos educacionais contemporâneos. Dessa maneira, iniciaremos tentando sinalizar para as idéias mais fecundas para psicólogos ou profissionais cujo objetivo é a eficiência do processo educativo.

\section{A Teoria Psicogenética de Piaget e Sua Contribuição à Prática do Psicólogo no Contexto Escolar}

A teoria psicogenética de Jean Piaget ganhou espaço no panorama educacional brasileiro entre 1970 e 1980. Embora seu interesse fosse epistemológico e não pedagógico, foi pela vertente da Educação que ficou conhecido no Brasil, através das "fachadas" de escolas que divulgavam: "usamos o Método Piagetiano". No entanto, o construtivismo piagetiano foi grosseiramente interpretado, gerando equívocos em relação à compreensão de como se dá a construção do conhecimento nessa perspectiva.

A idéia de construção do conhecimento proposta por Piaget defende que é na interação com o meio que o sujeito se depara com situações diferenciadas, que o levam a construir hipóteses, através dos processos de assimilação e acomodação, visando explicar os fenômenos que ocorrem no seu mundo. Piaget, um biólogo de formação, defendia na sua teoria "epistemológica genética" um duplo sentido para a idéia de "gênese": origem (a priori) e genético (orgânico, maturacional). Assim, os conceitos teóricos de base foram emprestados da Biologia - estrutura, reflexos, esquemas etc. - e a partir daí transpostos para uma abordagem psicológica.

Alguns resultados de pesquisa (Salvador e cols., 2000) mostram que quando o sujeito não consegue assimilar novos conhecimentos aos seus esquemas surgem os desequilíbrios, os conflitos cognitivos, fato que o leva a buscar uma equilibração, com o objetivo de adaptar-se ao meio. É a busca desta adaptação - equilibração majorante (Piaget, 1976) — o cerne do desenvolvimento cognitivo, que segue estágios nos quais o sujeito raciocina 
de maneiras diferentes, suscitando conflitos de naturezas diversas que promovem o seu progresso cognitivo estrutural. Embora a ênfase não devesse estar, como geralmente tem acontecido, nestes estágios.

O conceito piagetiano de equilibração mostra como uma criança é capaz de resolver uma situação de conflito suscitada pela presença simultânea de esquemas cognitivos contraditórios. Este processo, que levaria a criança para um equilíbrio superior, é considerado por Piaget (1976) como um processo de auto-regulação estritamente interno ao sujeito. $O$ mecanismo da equilibração se explica pelo fato que cada uma das etapas sucessivas apresenta uma probabilidade crescente em função dos resultados obtidos na precedente.

As estruturas biológicas em interação com o ambiente são tidas como a base principal na qual a inteligência opera: há uma prioridade da dimensão biopsicológica sobre a dimensão social. Segundo Piaget (1976), o social é importante para o desenvolvimento mental das crianças, mas não estruturante deste desenvolvimento como o é, por exemplo, para Vygotsky. É necessário refletir sobre a história de Piaget e as influências desta na sua abordagem teórica. Ele toma emprestado, por exemplo, a noção de adaptação do contexto biológico e a transforma no eixo principal: "Trata-se da idéia de que o que chamamos de conhecimento não tem, nem pode ter, o propósito de produzir representações de uma realidade independente, mas antes tem uma função adaptativa" (Fosnot, 1998, p. 19).

No cenário escolar, a construção do conhecimento é propiciada pela relação professor-aluno-conhecimento. Sem negar as especificidades do conteúdo escolar — que é situado historicamente, apresenta uma marca cultural e um ambiente social definido - a aquisição de muitos construtos conceituais apenas parece viável pela mediação de um professor, que tem a função de fornecer ao ambiente de sala de aula o espaço onde se realizará a construção de um saber ensinado que não é claro, transparente, e assim, constrói-se na tentativa de transformar o conhecimento científico em objeto de ensino, conforme a idéia de transposição didática, proposta e discutida por Chevallard (1985).

No entanto, numa macro-visão, as escolas não têm demonstrado preocupação em preparar bem os seus alunos para a aquisição de conceitos, mas sim para "treinálos a aprender", excluindo a significação e contextualização dos modelos utilizados, bem como deixando de considerar (em grande parte) os conceitos construídos por eles nas suas experiências cotidianas. A maioria dos professores pensa que é suficiente propor um discurso sobre um conteúdo, transmitindo conceitos científicos em aulas exclusivamente expositivas, como "verdades absolutas", perpetuando a visão do conhecimento como 'cópia', inscrita numa tabula rasa. Dessa forma, gera-se um grande problema para a aprendizagem, pois o objetivo é apenas a transmissão do conteúdo que se deseja ensinar, descartando qualquer elaboração de real construção do conhecimento por parte do aluno. Essa questão é analisada por Larocca (2000) da seguinte forma:

"Na área educacional, vem-se repetindo historicamente o que se pode chamar de 'seqüestro' de determinadas teorias psicológicas para propiciar fundamento científico à reformulação gestada por certas políticas educacionais. Freqüentemente (...), a perspectiva teórica adotada é apresentada aos professores através de processos massivos de capacitação, como se fosse a única ou última palavra válida sobre desenvolvimento e aprendizagem ... Criam-se, dessa maneira, modismos psicológicos na Educação e a cada alteração que ocorre nas equipes dos governos, os professores são chamados a aderir a um "novo remédio milagroso" (p. 63).

Além disso, as tais capacitações costumam acontecer de forma mecânica, apenas expositiva e desarticulada da prática, ou seja, diz-se aos professores "façam o que digo (com os alunos), mas não façam o que faço com vocês (os professores)". Este aspecto remete ao tipo de posicionamento que é assumido pelos profissionais dentro do cenário escolar com relação a como se origina/ constrói o conhecimento. Nesta posição teórica, Piaget e seus discípulos defendem uma visão 'interacionista', acreditando que o conhecimento é produto da interação entre sujeito e meio ambiente, construindo-se gradativamente em etapas com a participação ativa do sujeito, permitindo o desenvolvimento de sua cognição e, conseqüentemente, promovendo a aquisição do conhecimento específico.

É inegável a contribuição que essa teoria trouxe, mesmo que de forma tão equivocada inicialmente, para a análise crítica do Modelo Tradicional nos moldes behavioristas. Como defendido por Souza e Kramer (1991, citado por Larocca, 2000):

"Não se pode desconsiderar as contribuições de Piaget, da mesma forma que não se pode difundir a obra ou o pensamento de Vygotsky como se fosse a última e única palavra dita sobre o desenvolvimento infantil e sobre o trabalho com a criança. Não devemos, nesse sentido, repetir com Vygotsky, nos anos 90, o que foi feito com a obra de Piaget, nos anos 70, (...). Simultaneamente, não podemos menosprezar agora o trabalho de Piaget, (...) mais do que precipitadamente optar por uma das duas abordagens, é preciso indagar a respeito dos paradigmas que nortearam seu pensamento, suas investigações e as teorias que 'contribuíram" (p. 63).

Piaget traz significativas mudanças, por exemplo, na maneira de se encarar o erro, tido anteriormente como 
algo a ser severamente combatido. Para os construtivistas — segundo Astolfi (1997) — ao contrário, o erro é mais positivo, e seu papel e importância precisam ser considerados e estudados com outro olhar na construção do conhecimento, uma vez que indica o progresso conceitual a ser obtido. As respostas dos alunos, por mais absurdas que possam parecer, são importantes para compreender as operações intelectuais que estão em jogo. Além disso, os "construtivistas" defendem que só quando a pessoa tem capacidade de experimentar as ferramentas de que dispõe, às novas situações que encontra, é que ela progride. O erro implica, nesta perspectiva, qual a lógica de pensamento do aluno num dado momento da construção de seus esquemas conceituais. Compreendendo como o aluno raciocina sobre determinado conceito, o professor pode propor situações de intervenção significativas para a superação de tais assimilações incompletas ou incorretas.

Outra contribuição importante, embora ainda pouco aproveitada no contexto escolar, refere-se ao desenvolvimento do julgamento moral. Piaget defendeu, por exemplo, que a compreensão das regras e de outros conceitos morais (como fraude, mentira, justiça) caminha junto com o desenvolvimento intelectual, está relacionada a este, e possui características específicas; portanto, tais regras devem ser construídas e não impostas. É possível verificar que esta construção, que vai refletir diretamente nas questões relacionadas à indisciplina/disciplina, também precisa da colaboração do adulto, através de experiências e relações de respeito mútuo. Dessa maneira várias contribuições podem ser destacadas.

A partir da teoria de Piaget é possível tomar algumas considerações como diretrizes educacionais:

"outorgar ao aluno um papel central em suas aprendizagens, aceitar que o processo de aprendizagem é um processo reconstrutivo, lento, no qual o aluno deve carregar o peso da atribuição de significados, pensar que o processo de equilibração é essencial em qualquer construção de conhecimentos, defender que o ensino deve favorecer as situações nas quais ocorra essa aprendizagem significativa e que não deve ser um processo mecânico e repetitivo, etc" (Martí, 1996, p. 23).

Nestes termos, segundo Coll (1996), podemos abstrair três princípios básicos sobre o funcionamento do psiquismo humano a partir da teoria genética, que orienta a análise, a explicação e a compreensão dos processos de Educação escolar: a) os esquemas de ação e representativos - que dão a capacidade de interpretação e de significado - são mediadores dos intercâmbios funcionais que mantemos com nosso meio; b) a importância da atividade mental construtiva no funcionamento do psiquismo humano - conhecer é atuar sobre a realidade, e esta atividade tanto pode ser externa, observável, como pode ser mental, não observável; c) o modelo de equilibração, proposto para dar conta da dinâmica da mudança e do progresso intelectual, é uma tendência natural do psiquismo humano que explica e torna possível a atuação de outros fatores.

Neste sentido, várias conseqüências são produzidas pelos pressupostos piagetianos para a ação do psicólogo escolar. É fundamental, por exemplo, a compreensão de que o problema da aprendizagem implica no problema do conhecimento, e que está diretamente relacionada a "visão de mundo" adotada por esse profissional. Piaget (1976, citado por Ramozzi-Chiarottino, 1994) defende que "aprender é saber realizar (réussir); conhecer é compreender e distinguir as relações necessárias das contingentes: atribuir significado às coisas no sentido mais amplo da palavra, ou seja, levando em conta não só o atual e explícito como o passado, o possível e o implícito" (p.73).

Por outro lado, a ação deste psicólogo exige clareza dos pressupostos teóricos para a transposição “experimental". Para Piaget (1976, citado por RamozziChiarottino, 1994) entre a reflexão filosófica e a ação do psicólogo existe um "abismo", o qual o próprio Piaget tentou preencher através das suas investigações durante toda a sua vida de pesquisador. Para isso, faz-se necessária a compreensão, por parte desse profissional, de que se a grande descoberta deste autor foi o processamento cognitivo,

“(...), ou seja, como é possível ao ser humano aprender, conhecer e atribuir significado, caracterizando o conhecimento não como cópia interior dos objetos ou dos acontecimentos, mas como uma compreensão do modo de construção ou de transformação desses objetos e acontecimentos, então há uma conseqüência necessária para a prática da Psicologia” (p. 74).

Dessa maneira, o papel deste profissional na escola deveria ter como subsídio principal a compreensão dessa dinâmica.

\section{A Teoria Sócio-Histórica de Vygotsky e a sua Contribuição à Prática do Psicólogo no Contexto Escolar}

A outra perspectiva teórica a ser discutida, e relevante para a atuação do psicólogo escolar, é a sócio-histórica. Tomamos a liberdade de nos referirmos aos pressupostos de Vygotsky como teoria. Este ponto, por si só, geraria uma longa e polêmica discussão, pois há os que defendem que Vygotsky não propôs uma teoria organizada a partir de pressupostos e postulados bem definidos. De fato, Vygotsky não dispôs de muito tempo para a sua elaboração teórica. Morreu jovem, deixando toda uma obra por desenvolver. Apesar disso, reconhece- 
se que o legado teórico deixado por Vygotsky é rico e profundo, portanto não pode ser compreendido, se analisado de maneira superficial. Nesta perspectiva, a sua teoria é em essência, dialética - no sentido que propõe Hegel - não podendo ser compreendida sem considerar a interdependência entre os conceitos propostos. Dessa interdependência, surge algo novo, diferente do que cada conceito significa isoladamente, na mais autêntica idéia de síntese dialética.

A teoria de Vygotsky foi uma das mais debatidas, ou citadas, em Educação na última década. Falar deste autor e de suas contribuições à reflexão sobre o processo ensino-aprendizagem requer que façamos uma análise do contexto em que foi produzida, bem como em que circunstâncias ganha vulto no Brasil. Esse argumento já aponta para uma visão "vygotskyana": um conhecimento produzido dentro de um contexto histórico, por um homem igualmente contextualizado e inserido em um tempo histórico. Isso é válido para qualquer análise científica.

A melhor forma de fazer referência à teoria sóciohistórica é analisá-la em relação a outras teorias, principalmente se considerarmos a inserção destas no cenário educacional do nosso país. Do ponto de vista do cenário político-educacional do Brasil, podemos situar superficialmente a influência das teorias psicológicas na Educação da seguinte forma: na década de 70 tivemos uma forte influência do Behaviorismo, sobretudo em sua versão contemporânea, representada por Skinner e outros psicólogos americanos. Contextualizando essa afirmação, a década de 70 foi fortemente marcada pelo regime e ditadura militar. A escola, então, passa a ser compreendida como um pequeno 'quartel', onde os comportamentos deveriam ser modelados a partir de contingências de reforço. Controlando a relação entre Estímulo-RespostaReforço/Punição, poderíamos dar conta do processo de aprendizagem, no qual o conhecimento passaria a ser concebido como uma cópia do real. Essa perspectiva promoveu mudanças radicais na Educação, instituindo o tão conhecido - e criticado - 'modelo tradicional de Educação', não mais nos moldes 'tradicionais' antigos, no qual o professor era percebido como um tutor e o processo centrava-se nele, mas a partir de uma perspectiva tecnicista.

A década seguinte é marcada pela abertura política e queda da ditadura militar. Como discutido anteriormente, é nesse contexto que a teoria de Piaget é enfocada no cenário educacional do Brasil. Com Vygotsky, o processo não foi diferente. Embora este teórico fosse contemporâneo de Piaget, apenas no final da década de 80 e início dos anos 90 sua teoria passou a ser discutida e divulgada amplamente. Ele começa a desenvolver tal teoria após a Revolução Russa de 1917, propondo transpor o marxismo do nível sociológico para o nível psicológico, embora seus pressupostos teóricos propusessem uma dimensão individual (além da social) na construção do conhecimento.

A idéia inicial - e "perigosa" - era que Vygotsky vinha acrescentar à teoria de Piaget o "social", surgindo termos como "Sócio-Construtivismo", que culminam por acentuar esta visão equivocada. A partir da análise das idéias fundamentais da teoria sócio-histórica, poderemos refletir em que medida essa construção teórica tem implicações para o processo ensino-aprendizagem e como a Psicologia pode mediar a apropriação dessas no universo escolar; através de alguns conceitos que explicam o desenvolvimento das funções mentais superiores tipicamente humanas - e suas implicações educacionais.

As principais idéias de Vygotsky referem-se: (1) à relação dialética entre indivíduo-sociedade, nas quais originam-se as características tipicamente humanas. $\mathrm{O}$ homem transforma o seu meio e, ao mesmo tempo, transforma-se a si mesmo; (2) às funções psicológicas superiores, que se originam nas relações entre o indivíduo e seu contexto sócio-cultural, ou, em outras palavras, têm uma origem cultural; (3) à relação com o mundo, que seria mediada por "ferramentas" criadas pelo homem; (4) ao cérebro como a base biológica de tais funções mentais. Mas o cérebro não seria imutável ou fixo, podendo-se falar em "plasticidade cerebral". A partir dessa reflexão entende-se que "os processos psicológicos complexos se diferenciam dos mecanismos mais elementares e não podem, portanto, ser reduzidos à cadeia de reflexos" (Rego, 1998, p. 43).

Assim, uma concepção fundamental que Vygotsky traz à reflexão é a idéia de que o conhecimento não se dá a partir da interação direta sujeito-objeto. Essa interação é, em essência, mediada. Com isso, ele propõe a idéia de mediação, tendo por base a concepção de Marx e Engels, realizada pelos instrumentos e signos. Os instrumentos são objetos do mundo físico, aqueles que mediam a ação (e transformação) do homem sobre a natureza. A possibilidade de transformação desta pelo homem seria infinitamente menor se ele não houvesse desenvolvido e aprimorado os instrumentos que auxiliariam a sua intervenção no mundo. Os signos aparecem como os instrumentos psicológicos, pois eles mediam o próprio pensamento.

A linguagem se constitui como o signo fundamental, tendo o poder de representar simbolicamente objetos e eventos. Na ausência de um objeto, ele pode ser representado através da linguagem sem que haja necessidade de tê-lo concretamente ao alcance das mãos. Logo, a 
linguagem teria uma dupla função, como discutido em Oliveira (1993), a de "intercâmbio social"e a de "pensamento generalizante". Neste sentido, Vygotsky atribui um papel fundamental à linguagem, na constituição das funções mentais superiores, pois mais do que comunicar o pensamento tem a função de organizá-lo e estruturá-lo.

A escola aparece como elemento mediador na apropriação, pelo indivíduo, do saber historicamente acumulado ao longo do desenvolvimento da humanidade. Nessa perspectiva teórica, assume um papel primordial, pois "a instituição escolar foi criada para desempenhar uma função: a de comunicar às novas gerações os saberes socialmente produzidos, aqueles que são considerados, em um determinado momento histórico, válidos e relevantes" (Lerner, 1996, p. 95). E a linguagem, enquanto instrumento estruturante do pensamento, deve ser explorada nesse contexto como forma de representação e organização interna do mundo externo.

Mas a linguagem não pode ser percebida apenas como expressão verbal. Diversas formas de linguagem devem ser exploradas no contexto escolar: verbal, escrita, gráfica, pictórica, numérica etc. Os Parâmetros Curriculares Nacionais, elaborados pelo Ministério da Educação e Cultura - MEC (1997), apontam para essa reflexão, tanto no que diz respeito à intervenção didática quanto ao processo de avaliação. Um único instrumento e forma de expressão lingǘstica não pode dar conta do quanto o aluno aprendeu, do saber do qual se apropriou ao longo de um período letivo. Esse saber científico, apropriado no contexto escolar, não pode prescindir das experiências cotidianas do indivíduo e do acervo de conhecimento que ele acumulou ao longo de suas vivências no cotidiano escolar e extra-escolar. Isso nos remete a outra análise extremamente produtiva da teoria de Vygotsky, a relação entre conceitos cotidianos e conceitos cientificos no processo de formação de conceitos.

Em sua reflexão teórica sobre o processo de formação de conceitos, a discussão acerca dos conceitos cotidianos e científicos, e das relações entre estes, configura-se como um dos aspectos mais importantes desta abordagem. Ambos os conceitos fazem parte de um processo mais complexo e estão intimamente relacionados no seu interior. Para adquirir determinados conceitos científicos, a criança precisa ter consolidada a compreensão dos cotidianos que lhes dêem suporte. Nessa relação, os conceitos cotidianos favorecem o desenvolvimento dos científicos, conferindo-lhes maior "concretude", ou seja, relacionando-os com o dia-a-dia. Os conceitos científicos, por sua vez, dão abrangência e maior poder de generalização aos cotidianos. Desta forma, ambos são imprescindíveis e complementares para o processo.

Se analisarmos a relevância disto para a Educação, perceberemos que a escola freqüentemente "descon- textualiza" os conceitos por ela trabalhados, não levando em consideração que o aluno tem um acervo de experiências e conhecimentos anteriores - escolar e extraescolar - que deveria servir como suporte para a construção de novos conhecimentos. Em contrapartida, os novos conceitos elaborados precisam ser "funcionais", de acordo com a reflexão atual em Psicologia, Pedagogia e Didática. Ou seja, o aluno necessita entender o "por quê" e "para quê" daquela aprendizagem. Isso tem implicações tanto do ponto de vista cognitivo quanto do afetivo e motivacional. O estudante passa a se sentir mais valorizado, pois suas experiências são consideradas e discutidas no contexto da sala de aula, e os conhecimentos escolares tornam-se mais funcionais. Desta forma, a escola pode ser percebida como um ambiente mais interessante e prazeroso.

Sobre os processos de desenvolvimento e de aprendizado Vygotsky propõe uma análise complexa. Uma das reflexões mais instigantes para o educador é a de que o bom ensino é aquele que se adianta ao desenvolvimento (Rego, 1998), reflexão que abre caminho para outro conceito fundamental: o de Zona de Desenvolvimento Proximal (ZDP). Este conceito pode ser compreendido como a distância entre o que o aluno é capaz de realizar sozinho, já consolidado em seu desenvolvimento (nível real) e aquilo que ele não pode fazer sozinho, mas consegue realizar na interação com o outro mais experiente (nível potencial; Vygotsky, 1991).

Esta análise implica, primeiramente, que não é preciso esperar até que o aluno esteja "pronto" (do ponto de vista do desenvolvimento) para adquirir um determinado conhecimento. Isto desmistifica a idéia de "prontidão", amplamente difundida e colocada em cheque pelas idéias de Piaget. A teoria dos estágios, com sua proposta de etapas seqüenciais e universais de desenvolvimento, foi muitas vezes mal compreendida pelos educadores que tomaram isoladamente um aspecto discutido por Piaget, no qual o aluno só poderia aprender aquilo que estivesse dentro da estrutura cognitiva de um determinado estágio.

A segunda implicação é a idéia de que a escola deve valorizar, especialmente, as interações entre os diferentes. Assim, a concepção de que salas de aula heterogêneas são preocupantes também se desfaz, pois interações diversificadas implicam em indivíduos com diferentes ZDPs, interatuando uns nas ZDPs dos outros. O aluno menos experiente se beneficia dessa interação, pois o outro pode ajudá-lo em elaborações que ele não consegue realizar individualmente. $\mathrm{O}$ mais experiente também se beneficia, pois no momento em que procura ajudar o outro a desenvolver novos conceitos reorganiza e reestrutura suas próprias concepções, a fim de sistematizálas e compartilhá-las. 
A teoria sócio-histórica se consolidou, a partir destas teses, como uma teoria de extrema valia para a Educação. As idéias construtivistas, na atualidade, não podem estar desvinculadas da proposição teórica de Vygotsky. Há, de fato, um caminho a ser percorrido, uma distância entre os aspectos teóricos aqui discutidos e a transposição destes para uma prática escolar cotidiana. Não se pode fazer simplesmente uma justaposição; adaptações necessitam ser realizadas. Mas é preciso transformar, e toda transformação, como bem propôs Vygotsky, produzirá algo novo, que não será a soma das questões teóricas às práticas, mas o produto dessa interatuação, uma síntese dialética. E esta tarefa deveria ser mediada pelo psicólogo escolar.

\section{Considerações Finais}

Neste artigo, resgatamos diretrizes para uma atuação mais eficiente do psicólogo e sugerimos a apropriação e mediação de conceitos, ambas imprescindíveis ao cenário escolar. O objetivo, então, foi favorecer discussões sistemáticas dos temas apresentados, uma vez que esta tem sido a prioridade encontrada em diversos contextos escolares. Neste sentido, sugerimos a apropriação de uma estrutura de atuação essencialmente contextualizada, em equipe e mediadora das contribuições da Psicologia Cognitiva. Assim, trouxemos as idéias mais discutidas de autores que se constituem como os pilares de teorias que influenciam o cotidiano de uma instituição que se pretende promotora da aprendizagem. Nestas abordagens, procuramos demonstrar que falar em Piaget e Vygotsky, mesmo que de forma introdutória, significa trazer conceitos extremamente complexos e relacionados entre si e que, portanto, não convém, como vem acontecendo freqüentemente, serem vulgarizados ou tratados de forma superficial e até simplista.

Observa-se nesta discussão, em primeiro lugar, a impossibilidade de falar das contribuições da Psicologia Cognitiva sem falar em Interacionismo (precisando, então, diferenciá-lo das demais correntes filosóficas) e, assim, sem falar em Piaget e Vygotsky. Em segundo lugar, demonstra-se a dificuldade de se abordar o primeiro sem tratar do epistemológico, do método clínico, dos invariantes funcionais, da equilibração, da ação sobre o conhecimento, do julgamento moral, do erro e da avaliação como parceiros da construção do conhecimento, entre outros. Da mesma forma, é difícil abordar Vygotsky sem trazer conceitos como funções psicológicas superiores, interação, mediação simbólica, instrumentos e signos, zona de desenvolvimento proximal, formação de conceitos, entre outros.

Verificamos, desta maneira, que temos um "arsenal psicológico" oferecendo elementos que dão suporte à análise constante do processo educativo, e através de diversas "lentes". Logo, o psicólogo se torna o profissional mais indicado a suscitar e instigar tal empreitada no cenário escolar, sem, no entanto, prescindir das contribuições de todos os setores deste e, especialmente, da prática dos profissionais que formam, com ele, a equipe pedagógica e a escola.

Contudo, precisamos enfatizar ainda alguns pontos relevantes que deverão permear as reflexões que este profissional conseguir implementar. Iniciaremos com pontos curiosos a respeito de Piaget e Vygotsky, que sozinhos já sugerem relações com o nosso dia-a-dia de sujeitos cognoscentes e principalmente com a escola. Estes estudiosos têm características comuns e especiais, uma delas é a interdisciplinaridade - precisamos aprender isso sob diversos aspectos. Tanto Piaget como Vygotsky lançaram mão do estudo e da análise de diferentes ou correlatas áreas de conhecimento, correntes filosóficas e disciplinas. Eles procuraram questionar, integralizar, relacionar ou contrapor idéias e temas aparentemente distantes. Como poderíamos então pensar em ter que escolher uma entre quaisquer que sejam as teorias? Martí (1996) interpreta uma proposição de Coll (1996), que ilustra bem essa reflexão: "Coll reivindica a pertinência de alguns postulados da teoria genética ..., embora afirme que tais postulados devam ser reelaborados de acordo com o significado da prática educacional e em relação a outros postulados provenientes de outras teorias" (p. 30).

Um outro ponto também nos traz elementos ricos à reflexão. Toda mudança ou transformação requer ousadia, pois significa, de início, desafio, autocrítica, argumentação, avaliações constantes e objetivos claros. Aqueles autores, por exemplo, não tinham sequer um método de pesquisa psicológica que alcançasse seus questionamentos. Em outro sentido, não encontraram "em seu meio científico uma Psicologia adequada que lhe permitisse abordar as suas questões teóricas fundamentais. Precisou inventá-la" (Martí, 1996, p. 20); o que vale tanto para Piaget como para Vygotsky. Eles precisaram inclusive romper com a Psicologia de suas épocas, ou seja, de ousadia e demais características citadas.

Por fim, é importante esclarecer que ao nos referirmos ao "construtivismo" incluímos tanto os postulados de Piaget como os de Vygotsky, pois o construtivismo tem origem fundamental na pesquisa epistemológica do primeiro e sócio-histórica do segundo, entre outros posteriores. Como poderíamos, se temos a intenção de atuar no cenário escolar, deixar de analisar e, principalmente, aprofundar os conhecimentos nesta teoria?

Fosnot (1998) consegue em alguns pequenos trechos resumir brilhantemente a quê o construtivismo vem e com o quê se compromete quem se propõe a compartilhar dos 
pressupostos desta teoria. Por este motivo finalizaremos este ensaio com citações que tanto demonstram a amplitude, a importância e as possibilidades de articulações, a partir do estudo desta, como trazem sérios alertas:

“... uma visão construtivista da aprendizagem sugere uma abordagem do ensino que oportunize aos alunos experiências concretas, contextualmente significativas, nas quais eles possam buscar padrões, levantar suas próprias perguntas e construir seus próprios modelos, conceitos e estratégias. (...) corremos o risco de promover reformas de curta duração, a menos que os educadores entendam a teoria por trás da prática (grifo nosso), as conexões entre as disciplinas envolvidas nas reformas e a necessidade de uma grande reestruturação das escolas e dos programas..." (ps. xi e xii).

O psicólogo escolar, portanto, não pode prescindir destes conhecimentos e deve mediá-los no contexto educacional. Gostaríamos de enfatizar ainda a premência de uma coordenação entre tais teorias, uma vez que a "pergunta importante a ser feita não é se o indivíduo cognoscente ou a cultura deveriam receber prioridade em uma análise da aprendizagem, mas como é a interação entre eles" (Fosnot, 1998, p. 40).

\section{Referências}

Astolfi, J. P. (1997). L'erreur, Um outil pour enseigner. Paris: Esf.

Chevallard, Y. (1985). La transposition didactique: Du savoir savant au savoir enseigné. Paris: La Pensée Sauvage.

Coll, C. (1996). Piaget, el construtivismo y la educacion escolar: Donde está el hilo condutor? Em C. Coll do Organizador (Org.), Substratum (Vol. III, pp. 8-9). Porto Alegre: Artes Médicas.

Correia, M. F. B. (1997). Como o psicólogo escolar está atuando na sua função de mediador entre o conhecimento acadêmico e a Educação? [Resumo]. Em Sociedade Interamericana de Psicologia (Org.), Resumos de comunicą̧ões cientificas, XXVI Congresso Interamericano de Psicologia (p. 240). São Paulo, SP: SIP.
Correia, M. F. B., Oliveira, I. C. \& Andrade, K. L. (1998). Conhecimento dos educadores sobre as contribuições da Psicologia para a Educação. [Resumo]. Resumos científicos do IV Congresso Nacional de Psicologia Escolar (p. 68). João Pessoa, PB: ABRAPEE.

Correia, M. F. B., Lima, A. P. B. \& Campos, H (1999). Proposições e dificuldades da atuação do psicólogo no contexto escolar. [Resumo]. Anais do I Congresso N/NE de Psicologia. Salvador, Ba: CRP, UFBa.

Correia, M. F. B. \& Campos, H. (2000). Psicologia escolar: Histórias, tendências e possibilidades. Em O. H. Yamamoto \& A. Cabral Neto (Orgs.), O psicólogo e a escola (pp. 59-97). Natal, RN: EDUFRN.

Fosnot, C. T. (1998). Construtivismo: Teorias, perspectivas e prática pedagógica. Porto Alegre, RS: ArtMed.

Larocca, P. (2000). O saber psicológico e a docência: Reflexões sobre o ensino de psicologia na educação. Psicologia: Ciência e Profissão, 20, 6065.

Lerner, D. (1996). O ensino e o aprendizado escolar: argumentos contra uma falsa oposição. Em J. A. Castorina, E. Ferreiro, D. Lerner \& M. K. Oliveira (Orgs.), Piaget e Vygotsky: Novas contribuições para o debate (pp. 85-146). São Paulo, SP: Ática.

Martí, E. (1996). Introdução: A atualidade de Jean Piaget. Em NOME do Organizador (Org.), Substratum (Nol. I, N. 01, pp. 13-35). Porto Alegre: Artes Médicas.

MEC (1997). Parâmetros Curriculares Nacionais. Brasília: Ministério da Educação e Cultura.

Moreira, M. H. C. (1994). Psicologia e educação: Uma história de parcerias e indagações. Cadernos de Psicologia, 2, 5-9.

Oliveira, M. K. (1993). Vygotsky: Aprendizado e desenvolvimento, um processo sóciohistórico. São Paulo, SP: Scipione.

Patto, M. H. S. (1984). Introdução à psicologia escolar. São Paulo, SP: Queiroz.

Piaget, J. (1976). A equilibração das estruturas cognitivas. Rio de Janeiro, RJ: Zahar.

Ramozzi-Chiarottino, Z. (1994). Em busca do sentido da obra de Jean Piaget. São Paulo, SP: Ática.

Rego, T. C. (1998). Vygotsky: Uma perspectiva sócio-cultural da educação. Petrópolis, RJ: Vozes.

Salvador, C. C, Alemany, I. G., Martí, E., Majós, T. M., Mestres, M. M., Goñi, J. O., Gallart, I. S. \& Giménez, E. V. (2000). Psicologia do ensino. Porto Alegre, RS: Artes Médicas.

Vygotsky, L. V. (1991). A formação social da mente. São Paulo, SP: Martins Fontes.

Recebido: 30/10/2000

Revisado: $13 / 02 / 2001$

Aceite Final: 05/04/2001

Sobre as autoras:

Mônica F. B. Correia é Psicóloga, graduada pela Universidade Federal da Paraíba (UFPB), Doutoranda e Mestre em Psicologia Cognitiva pela Universidade Federal de Pernambuco (UFPE) e Especialista em Avaliações e Medidas em Psicologia (UnB). Atua como Coordenadora e docente da pós-graduação em Psicologia Educacional; docente e supervisora de estágio em Psicologia Escolar do Departamento de Psicologia da Universidade Federal da Paraíba. Seu interesse atual está dirigido às relações entre cultura e cognição e à produção de significados.

Anna Paula Brito Lima é Psicóloga formada pela Universidade Federal de Pernambuco. Mestre em Psicologia Cognitiva, pela mesma Universidade (UFPE). Professora de cursos de graduação e pós-graduação do Departamento de Educação da Universidade Federal Rural de Pernambuco. Pesquisadora na área de Psicologia da Educação Matemática, vinculada ao Laboratório de Pesquisa em Psicologia da Educação Matemática (LAPPEM - UFRPE/UFPE). Atualmente desenvolvendo interesse de pesquisa acerca do papel do discurso educacional na construção de conceitos matemáticos em sala de aula.

Cláudia Roberta de Araújo é Psicóloga, formada pela Universidade Federal de Pernambuco. Mestre em Psicologia Cognitiva e atualmente Doutoranda do Programa de Pós-Graduação em Psicologia também da UFPE. Professora de cursos de graduação e pós-graduação do Departamento de Educação da Universidade Federal Rural de Pernambuco. Pesquisadora na área de Psicologia da Educação Matemática, vinculada ao Laboratório de Pesquisas em Psicologia da Educação Matemática (LAPPEM - UFRPE/UFPE). Atualmente seu direcionamento de pesquisa integra os eixos da cognição e afetividade e suas possíveis relações com a construção da subjetividade do professor. 